\title{
Target practice: choosing target conditions for test accuracy studies that are relevant to clinical practice
}

When redrawing the figure for this Research Methods \& Reporting article by S J Lord and colleagues (BMJ 2010;343:d4684, doi:10.1136/bmj.d4684), we misplaced the words "no action," "monitor," and "treat" on the x axis. These decisions are based on clinical factors and so should have been placed in the body of the figure. The corrected figure is given here $\Downarrow$.

Cite this as: BMJ 2011;343:d6155

๑) BMJ Publishing Group Ltd 2011 


\section{Figure}

Disease that will benefit from treatment

$\square$ Clinically important disease

$\square$ Clinically unimportant disease

$\square$ All disease

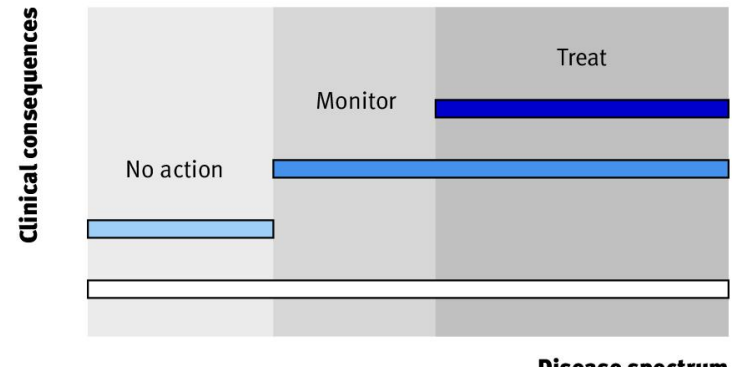

Disease spectrum 